\title{
Perinatal mortality in rural India: a strategy for reduction through primary care. I Stillbirths
}

\author{
USHA SHAH, A K PRATINIDHI, AND P V BHATLAWANDE \\ From the Department of Preventive and Social Medicine, B J Medical College, Pune, Maharashta, India
}

SUMMARY In a prospective community based study of the distribution and determinants of stillbirths in a rural area of Maharashtra, India, that was carried out for two years, 3129 singleton and 22 twin births were recorded in a population of 47000 . Of the 3173 babies, 85 singletons and five of the twins were stillborn giving a stillbirth rate of $28 \cdot 4 / 1000$ births. The causes of stillbirths are analysed and the possibility of reducing the unacceptably high stillbirth rate by adequate training of grassroot level workers in screening pregnant women for detection of "at risk" mothers and their timely referral is discussed.

The reported stillbirth rates from rural India are the highest among those reported from other countries in South East Asia such as Thailand, Burma, and Sri Lanka. There is a general belief that it is difficult to reduce the number of stillbirths under prevailing conditions. Many studies based on hospitals and dealing with fetal pathology are available. ${ }^{1-4}$ Nevertheless, most births in rural India ocur at home. A detailed study of the causes of stillbirths based on a rural community with a view to identifying possible interventions within the available resources is therefore essential.

We attempt to examine the extent and causes of stillbirths in a rural population of Maharashtra, India. Circumstances leading to stillbirths based on the analysis of data collected in a prospective study and interventions suitable at village level are discussed.

\section{Materials and methods}

The data for this analysis were collected during a two year prospective study of perinatal mortality based on a population of over 47000 living in 22 villages served by the rural Training Centre, Sirur, B J Medical College, Pune. The project was part of the Intercountry Perinatal Mortality Study in the South East Asia Region supported by the World Health Organisation.

From August 1977 to July 1979 every pregnancy was identified through specially trained female community health workers ( $\mathrm{CHW}$ ). One such worker covered a population of 25000,3000 by regular home visits every 15 days. Each pregnancy was followed up to its termination. Similarly, women coming into the study area for delivery were also covered. As each community health worker resided in the same village, she would know when any woman went into labour and could make a special visit to the family within 24 hours to investigate the cause of death. If the mother had had no antenatal care her pregnancy history was constructed through careful probing. Details regarding the birth were also recorded to assess the cause of death. This assessment was based on information given by relatives, traditional birth attendants, or the mother herself, as in most cases the delivery was not conducted by a doctor or nurse. The cause of death is therefore essentially based on lay reporting. ${ }^{5}$ No necropsies on the fetus were possible in the cultural setting. Hence pathology such as serious internal congenital anomalies, birth trauma causing cerebral haemorrhage, hyaline membrane disease, etc, could not be confirmed.

\section{Results}

During the study period of two years, 3129 singleton and 22 twin births were recorded. Of the 3173 babies, 90 were stillborn giving a stillbirth rate of $28 \cdot 4 / 1000$ births. Table 1 gives the cause of death in these 90 cases.

\section{A S P H Y XIA}

Asphyxia was responsible for 48 (53\%) of the stillbirths. The conditions leading to asphyxia were abnormal presentation 21 , prolonged labour 15 , and placental causes 13 . 
Table 1 Stillbirths by cause of death

\begin{tabular}{|c|c|c|}
\hline & Stillbirths & \\
\hline Cause of death & No & $\%$ \\
\hline Asphyxia & 48 & $53 \cdot 3$ \\
\hline Unexplained stillbirth & 16 & $17 \cdot 8$ \\
\hline Prematurity & 14 & $15 \cdot 6$ \\
\hline Intrauterine growth retardation & 4 & $4 \cdot 4$ \\
\hline Congenital anomaly & 4 & $4 \cdot 4$ \\
\hline Other & 4 & $4 \cdot 4$ \\
\hline Total & 90 & 100 \\
\hline
\end{tabular}

\section{Abnormal presentation}

Breech-Of the 18 still births among 42 breech deliveries, one was anencephalic and another extremely immature weighing only $950 \mathrm{~g}$. Hence the cause of death in these two cases was considered to be other than breeech presentation. In 16 of the 42 cases breech presentation led to difficulty in delivering the aftercoming head, resulting in fetal death. In four cases untrained birth attendants referred the patients to hospital after all attempts at home delivery had failed. One patient was referred for arrested aftercoming head. Fetal death had already occurred in all four cases on arrival at the hospital.

Transverse-All four cases with transverse lie were referred by the untrained birth attendants for prolapsed cord and hand when it was too late to save the baby.

Face-One of the two babies with face presentation was stillborn.

Prolonged labour was observed in 12 cases of cephalopelvic disproportion and three cases of uterine inertia.

Cephalopelvic disproportion-All 12 cases with cephalopelvic disproportion were term deliveries with birth weights above $2500 \mathrm{~g}$. One baby had hydrocephalus.

Uterine inertia-All three were term deliveries. One mother had had an earlier abortion and another a stillbirth.

Placental causes were responsible for 13 stillbirths.

Antepartum haemorrhage occured in eight out of 3151 women. Two of these women were referred to the teaching hospital for profuse bleeding, whereas others delivered at home. Of these eight births, five were stillbirths.

Cord prolapse occurred in eight patients, of whom three also had hand prolapse, hence they are considered under transverse presentation. The remaining five cases were multiparous women with vertex presentaion. Only one of the five babies was born alive and four had died of asphyxia.

Cord round the neck was seen in three cases. One was delivered by a trained dai and two by untrained birth attendants; all resulted in stillbirths.
Postmaturity leading to placental infarct was responsible for one stillbirth in a 19 year old primipara who had had no antenatal care.

\section{UNEXPLAINED STILLBIRTH \\ For 16 fresh stillbirths no cause could be determined.Three of these were among twins.}

\section{PRETERM BIRTH}

In three of the 14 preterm stillbirths the mother's health may have been responsible for premature delivery before 37 weeks of pregnancy.

One with heart disease had had two earlier abortions. One had oedema of feet suggestive of toxaemia and a history of premature stillbirth. The third woman complained of "prolapse" before onset of labour. In the remaining 11 preterm stillbirths premature onset of labour may have been due to twinning in one case, while in 10 cases no apparent cause for early onset of labour could be discovered.

INTRAUTERINE GROWTH RETARDATION

Severe maternal malnutrition (maternal weight $38 \mathrm{~kg}$ ) could be responsible for intrauterine growth retardation in one case. No apparent cause was seen in the remaining two cases.

\section{CONGENITAL MALFORMATION}

Four patients delivered at term had babies with anomalies of the central nervous system. Three had anencephalus and one spina bifida. Two of these women were primigravidas and the third had had an earlier stillbirth.

\section{OTHER CAUSES}

Maternal infection-Two stillbirths could have been due to maternal viral hepatitis. Both women had spontaneous premature deliveries, conducted by untrained birth attendants. One of these women died two days after delivery.

Maternal anaemia-A 19 year old primigravida was detected during third trimester as having $\mathrm{Hb}$ under $6 \mathrm{~g} / \mathrm{dl}$. Her family did not take her condition seriously nor the advice regarding need for urgent transfusion. She went into labour with $\mathrm{Hb} 2.5 \mathrm{~g} / \mathrm{dl}$ and delivered a stillbirth and died within $\mathbf{9 0}$ minutes of delivery.

Hydrops fetalis-One mother had a stillbirth with hydrops fetalis. She had had a previous full term normal delivery.

Sixty (67\%) mothers with stillbirths had no antenatal care as compared with 1707 (54\%) of 3151 women who had live births during the study period. The stillbirth rate among women with no antenatal care was $35 \cdot 1$ compared with 20.8 among women receiving antenatal care (table 2). The difference is statistically significant. Of the pregnant mothers, 
1970 out of 3151 (63\%) were delivered by untrained birth attendants, relatives, or without any help at all. Among these the stillbirth rate was $24 \cdot 8 / 1000$ births. Fourteen mothers out of $90(15 \%)$ with stillbirth had a history of stillbirth as compared with 98 of 3061 (3\%) with live births.

Table 2 Stillbirth rate by antenatal care

\begin{tabular}{llll}
\hline Antenatal care & No of mothers & $\begin{array}{l}\text { No of } \\
\text { stillbirths }\end{array}$ & $\begin{array}{l}\text { Stillbirth } \\
\text { rate }\end{array}$ \\
\hline No & 1707 & 60 & $35 \cdot 1$ \\
Yes & 1444 & 30 & $20 \cdot 8$ \\
Total & 3151 & 90 & 28.6 \\
\hline
\end{tabular}

$\chi^{2}=5 \cdot 507, \mathrm{p}=<0.05$.

\section{Discussion}

When most women have antenatal care and deliver in institutions having facilities for adequate intervention by skilled individuals, reducing the stillbirth rate may be difficult. In rural India home delivery conducted by an untrained person is the rule, and referrals, if any, are usually after the fetal death has occurred at home after a long period of trial labour.

Antenatal care from health centres is hardly ever sought or accepted when available and advice given during pregnancy is not taken seriously. As a result, stillbirth rates are high in rural India. It is unrealistic to expect this pattern of rural deliveries to change substantially in the near future and reduction must be attempted within the existing framework.

Of the 90 stillbirths studied, seven babies (4 with congenital anomalies, 1 with hydrops fetalis, and 2 whose mothers were suffering from infective hepatitis) can be considered unavoidable. Among the remaining 83 babies the most important cause of death was asphyxia. Of these, in 13 cases a placental or cord abnormality led to asphyxia. As these complications are diagnosed during labour, when transferring the patient in time is impossible, they may also be considered as unavoidable under present circumstances.

In the big group of "preterm delivery" three babies weighing below $1000 \mathrm{~g}$ would be unsalvageable in India.

Thus 23 of the $90(26 \%)$ still births may be considered as unavoidable under the prevailing conditions in India, but some intervention for the remaining $67(74 \%)$ stillbirths is possible.

Deaths due to birth asphyxia may be reduced by giving simple training to untrained birth attendants and community health workers. They can ascertain if the head is near the symphysis pubis by 34 weeks of gestation. The patient may be taken to a nurse or doctor for ascertaining the position of the baby if the head is not palpable in the usual position. The need to be delivered in an institution by adequately trained personnel has to be explained to all women with abnormal presentation. Similarly, these grass root workers may be trained to refer cases early and to refrain from giving prolonged trial labour at home. Usually there is a long delay before a referred patient can actually reach a hospital. This is due to the slow acceptance of such a need by the family and practical difficulties of transportation faced by the villagers. It is therefore necessary to train the birth attendants to suspect difficulty if labour does not progress satisfactorily after rupture of membranes and send for ANM while the baby is still alive. Some community health workers may even learn to detect a high fetal heart rate as an indication of fetal distress.

Simple resuscitation techniques taught to the birth attendants can save a considerable number of babies. In our experience village women can be trained to use efficiently the technique of mouth to mouth resuscitation. A substantial reduction in stillbirths due to asphyxia could thus be effected. Several unexplained stillbirths could be due t $\oplus$ non-recognition of risk factors during pregnancy an $\bar{\omega}$ an untrained attendant at such delivery. Some of 0 these stillbirths could be saved through antenataf care and trained help at delivery.

Preterm birth was considered the cause of death if 14 low birthweight babies. In three cases maternal it health may have been responsible for premature delivery. One more baby was a twin. At least in these four $(31 \%)$ cases antenatal care could have helped to identify the maternal illness and twins and special care been given to the mothers. In the remaining 10 cases no apparent reason for preterm delivery could be elicited. The hard farm work these women do until termination of pregnancy may be a predisposing factor for preterm onset of labour. Nevertheless, factors such as chronic malnutrition, repeated pregnancies, anaemia, etc may also have a synergistic influence along with physical strain. It is therefore not possible to establish a cause and effect relationship between exertion and preterm delivery.

In the absence of trained help at birth many of the preterm babies do not get the advantage of resuscitation as received by babies delivered by trained professionals. Hence contrary to data based on hospital statistics many stillbirths were observed among preterm babies in this community based study.

Had they availed themselves of antenatal care, $\tilde{\sigma}$ failure to gain weight and severe malnutrition could $N$ have been detected in three women who delivered low birthweight babies at term.

Since many women do not attend antenatal care at 
a health centre, cases of anaemia and toxaemia remain undetected. The community health workers could be trained to screen for these serious complications. The specific gravity method using copper sulphate solutions for estimation of $\mathrm{Hb}^{6}$ can be a satisfactory screening procedure to be used by community health workers after proper training. ${ }^{7}$ This procedure may be done in the home of any pregnant woman. Similarly, by training community health workers to detect pitting oedema on the feet and using uristicks for detection of albumin, patients with pre-eclampsia may also be identified at village level and then referred for confirmation of diagnosis and adequate treatment.

Clearly, therefore, a considerable number of stillbirths might have been prevented by identifying the risk factors during pregnancy and with skilled help at labour had these mothers had antenatal care. The main risk factors for stillbirth, identified through this study are lack of antenatal care, untrained birth attendants in abnormal labour, previous stillbirth, abnormal presentation, lack of knowledge and skill among untrained birth attendants of resuscitating the new born, and maternal malnutrition.

Owing to the large populations alloted to each primary health centre and the severe constraint of trained professionals, most pregnant mothers remain uncovered by the traditional $\mathrm{MCH}$ services. Ignorance about the need for antenatal care, especially in apparently normal pregnancy, results in many mothers not taking advantage of the available services. Hence, to improve the coverage of $\mathrm{MCH}$ services, it is necessary to involve the female community health workers and traditional birth attendants. According to the latest scheme for primary health care in India, each community health worker has a population base of 1000 , which is within easy reach. Being a member of the same community she is in a position to identify every pregnancy and offer primary care as well as serve as a link between the mother and the health centre staff.

Adequate training of these women could enable them also to screen all pregnant women at the village level to detect at risk mothers and persuade them to avail themselves of regular maternal and child health services.

\section{Conclusions}

Since in the absence of institutional facilities within easy reach women from rural areas will continue to deliver at home, the traditional birth attendants and community health workers will have to be adequately trained to

(1) Detect every pregnancy.

(2) Screen the mother for presence of one or more of the common risk factors such as (a) bad obstetric history, $(b)$ abnormal presentation by palpation of abdomen, (c) anaemia by $\mathrm{Hb}$ estimation (using CuSo4 specific gravity method ${ }^{6}$ or Talquist paper method), and (d) pretoxaemia-by detection of pitting oedema on the feet and albuminurea by uristicks.

(3) Refer at risk mothers to a nurse or doctor for special antenatal care.

(4) Conduct a normal delivery.

(5) Recognise signs of prolonged labour and take such cases to the nearest institutional facility for delivery before fetal death occurs.

(6) Resuscitate the asphyxiated baby by the simple technique of mouth to mouth respiration.

The community health workers can also be equipped with simple audiovisual aids to educate village women regarding various risk factors and their serious consequences. An awareness of danger to mother and baby can then help to improve acceptance of antenatal care and referral advice. With time all these can become common knowledge. Antenatal care as well as adequate delivery facilities will then be actively sought by the community.

\section{References}

${ }^{1}$ Shah, Deodhar P. Foetal loss. Journal of Obstetrics and Gynaecology, India 1972; 22: 663-9.

${ }^{2}$ Datta Banik ND, Sahe K. Factors related to perinatal mortality. Indian J Pediatr 1975; 42: 310-5.

${ }^{3}$ Ras PSS, Inbaraj SG. Extent of perinatal loss in south Indian urban and rural population. Indian Pediatr 1974; 12; 221-7.

- Puri RK, Verma IC, Choudhury P, Nalini P, Srinavasan S. Perinatal mortality-incidence and effect of various maternal factors. Pt 1. Indian J Pediatr 1981; 48: 297-304.

${ }^{5}$ World Health Organisation. Lay reporting of health information. Geneva: WHO, 1978.

- Philips et al. Copper sulphate specific gravity method. J Biol Chem 1950; 183: 305.

${ }^{7}$ Shah U, Pratinidhi AK, Bhatlawende PV, Alekar SV. Screening for anaemia by community health workers. World Health Forum (in press). 